OPEN ACCESS

Edited by:

Oliver Geden,

German Institute for International and

Security Affairs (SWP), Germany

Reviewed by:

Shinichiro Asayama, National Institute for Environmental

Studies (NIES), Japan

Manjana Milkoreit,

Purdue University, United States

${ }^{*}$ Correspondence:

Noel Castree

noel.castree@uts.edu.au

Specialty section:

This article was submitted to Negative Emission Technologies,

a section of the journa

Frontiers in Climate

Received: 04 October 2020 Accepted: 07 December 2020 Published: 23 December 2020

Citation: Castree N (2020) The Discourse and Reality of Carbon Dioxide Removal:

Toward the Responsible Use of Metaphors in Post-normal Times.

Front. Clim. 2:614014.

doi: 10.3389/fclim.2020.614014

\section{The Discourse and Reality of Carbon Dioxide Removal: Toward the Responsible Use of Metaphors in Post-normal Times}

\author{
Noel Castree ${ }^{1,2 *}$ \\ ${ }^{1}$ School of Communication, University of Technology Sydney, Sydney, NSW, Australia, ${ }^{2}$ Department of Geography, University \\ of Manchester, Manchester, United Kingdom
}

There's little doubt that a variety of CDR techniques will be employed worldwide in the decades and centuries to come. Together, these techniques will alter the character and functioning of the biosphere, hydrosphere, cryosphere, pedosphere, and atmosphere. More locally, they will have immediate impacts on people and place, within diverse national state contexts. However, for the moment CDR exists more in the realm of discourse than reality. Its future roll-out in many and varied forms will depend on a series of discussions in the governmental, commercial, and civic spheres. Metaphor will be quite central to these formative discussions. Metaphors serve to structure perceptions of unfamiliar phenomena by transferring meaning from a recognized "source" domain to a new "target" domain. They can be employed in more or less felicitous, more or less noticeable, more or less defensible ways. Metaphors help to govern future action by framing present-day understandings of a world to come. To govern metaphor itself may seem as foolhardy as attempting to sieve water or converse with rocks. Yet by rehearsing some old lessons about metaphor we stand some chance of responsibly steering its employment in unfolding debates about CDR techniques and their practical governance globally. This Perspective identifies some key elements of metaphor's use that will require attention in the different contexts where CDR techniques presently get (and will in future be) discussed meaningfully. Various experts involved in CDR development and deployment have an important, though not controlling, role to play in how it gets metaphorized. This matters in our age of populism, rhetoric, misinformation, and disinformation where the willful (mis)use of certain metaphors threatens to depoliticize, polarize, or simplify future debates about CDR. What is needed is "post-normal" discourse where high stakes decisions made in the context of epistemic uncertainty are informed by clear reasoning among disparate parties whose values diverge.

Keywords: discourse, metaphor, CDR, NETs, wicked problems, anticipatory semantics, discursive windows 
Discourses interest us not for their own sake but insofar as they comprise sites for the making of meaning .... The question is not whether material objects exist but how they become meaningful for us ... and thereby influence our actions. Epstein (2008: 8)

At long last, anthropogenic climate change-a key component of the emerging Anthropocene-is beginning to make itself fully felt in the realms of collective human decision making. The reality of global warming is now widely acknowledged, as is the significant future threat it poses; the massive inadequacy of current mitigation measures is no secret and denied only in fringe circles; meanwhile, in the relevant research communities (if not always the political community), talk of far-reaching "sustainability transitions" is now a common-place. The next 25 years could (and should) be game-changing for people and planet, even if few are talking seriously (yet) about a revolution in human affairs. Mitigation and adaptation measures will need to be ramped-up hugely. But they will need to be accompanied by a range of carbon dioxide removal (CDR) techniques designed to sequester greenhouse gases. Without them, global average temperature could make life in many parts of the future world distinctly inhospitable for millions of people, quite aside from its deleterious impacts on terrestrial and marine ecology.

In this context, a number of vitally important questions arise about CDR techniques, which range from biomass energy with carbon capture and storage (BECCS) through bio-char burial and afforestation to direct air capture and sequestration. This collection of papers is designed to begin to answer these questions. We are at an early stage in rolling-out $\mathrm{CDR}$ on a large scale. While some techniques are familiar (e.g., tree planting), others are novel and yet to be properly tested in real world settings (e.g., ocean alkalinization). The variety of possible techniques means that governing CDR responsibly will be complex, even within a single country. The perceived urgency of "tackling climate change" since the 2015 Paris Agreement was signed may propel rapid experimentation in the development, trialing, and implementation of certain CDR techniques. There are practical questions that have to be answered about public consultation, rules and regulations, planning permissions, and so on (e.g., see Fajardy et al., 2019, writing in this journal). But it's important not to lose sight of the discursive issues: how we talk about CDR requires close attention just as much as the material interventions gathered together under the CDR label. We have already seen this in discussions of solar radiation management (SRM) since around 2010. For some commentators, even to consider the possibility of SRM risks moral hazard, well before field- trials of things like stratospheric aerosol injection. The talk we talk affects whether and how we walk the proverbial walk.

It may seem foolhardy to talk about the governance of discourse, even in an informal sense of collectively monitoring and adjusting our language as we proceed. Words and their meanings, deployed in various communicative contexts, seem to elude social control: they evolve organically over time within and across whole societies. However, in this paper I want to focus on metaphors not language in general (for reasons to be explained). In addition, while I will make a set of general points about how CDR may in future be metaphorized, it's important to recall that some communicative contexts are more consequential than others. Trying to steer the use of metaphor in these contexts (e.g., public consultation exercises, reports commissioned by governments, or peer review articles) is a broadly viable proposition, whereas governing metaphor use in a wider society is probably not ${ }^{1}$-at least for the addressees of this article (namely, researchers interested in the technical, social, and environmental dimensions of CDR). My main concern in what follows is that ongoing discussions of CDR in the expert community and beyond become suitably "post-normal"-if not always, then as often as possible. That is, discussions should be attuned to the complex, high-stakes, urgent, value-based and uncertain character of CDR interventions seen as a family of specific, local/regional measures to be implemented over time across our variegated globe. Such discussion easily exceeds the language typically used by specialists to depict developments in science and technology.

Conventional uses of metaphor, I will suggest, could easily become barriers to post-normal discourse. While experts in linguistics and communication well understand the pervasive, necessary but often problematic character of metaphorical representation, people in the political, commercial, and civic spheres are often apt to use metaphor in partial, rhetorical, unthinking, manipulative, or strategic ways. This could hamper the sort of sophisticated, well-considered representations of CDR techniques that will help their implementation be as socially legitimate as it can reasonably be. Experts involved in the journey of CDR techniques from drawing board to actuality have a particular role to play in using metaphor well. This is especially important at a time when populist rhetoric, post-truth discourse, "alternative facts," fake news, and similar maladies afflict the public and political spheres worldwide.

While experts do not-and cannot-ultimately have a determining role in shaping public understanding of CDR, they arguably have a responsibility to counter manifestly deficient understandings of the technologies in question. Deficiency is not just a question of factual inaccuracy but also relates to the meanings conveyed through particular constellations of words. In the present case, the meanings can relate to (i) the practical efficacy of certain CDR techniques, (ii) to their wider knock-on effects socially and environmentally, and (iii) to the underlying rationale for their deployment in the first place. The unwary can easily elide metaphor use in these related but distinct contexts where questions of fact and value bleed into each other.

\section{CDR ON THE CUSP OF IMPLEMENTATION: ANTICIPATORY SEMANTICS AND METAPHOR}

As the COVID-19 pandemic reminds us, language is a necessary tool in any effort to devise suitable forms of action. New socioenvironmental problems, or new ways of addressing familiar

\footnotetext{
${ }^{1}$ That said, through laws and, over time, changing customs, societies do quite successfully govern language as the success of feminist and anti-racist arguments demonstrates in many countries across the world. Such governance responses tend to emerge out of widespread social discontent anchored in inequality, disrespect, or injustice.
} 
problems, call forth "anticipatory semantics:" that is, efforts to describe, explain, and evaluate situations so as to elicit, and justify, one or more practical responses intended to achieve (or avoid) certain future probabilities. ${ }^{2}$ In the case of the coronavirus, military language has been prevalent (e.g., COVID19 is an "enemy" and healthcare professionals are "heroes" working on "the front line" to protect the public). Likewise, social distancing and lock downs have been frequently depicted as necessary "circuit breakers." This sort of language serves to structure interactions between politicians and publics in a crisis situation. CDR is also being framed in the context of emergency: the last 3 years have seen scientists, activists, and others talk loudly of a looming "climate crisis" (Greta Thunberg being the personification of this). But, for better or worse, this second emergency is normally seen as less pressing than the first, even if the long-term threat it poses will be equally existential for many people and non-humans.

Presently, at the global level CDR is entering policy discourse because of (i) the very challenging Paris Agreement goal to keep average global temperature to a 2 degree Celsius rise or less, and (ii) the fact that CDR is built-into various scenarios prepared by the Intergovernmental Panel on Climate Change. Increasingly also called "negative emissions technologies" (NETS), CDR techniques will now start to feature meaningfully in national policy discussions about future plans for energy supply, nature conservation, transportation and more besides. People like me, and the other contributors to this special issue, can shape these discussions through our own language, advice, and interventions beyond the university's walls. But politicians, business people, civil servants, and citizens will have their say too. Parliamentary debates, white papers, United Nations meetings, company strategic plans, and public consultations are just some of the places where CDR techniques will be considered by a range of interlocutors, quite aside from their representation in the news media. A linguistic meshwork will emerge, with plenty of crossreferencing. As noted, while some techniques are scarcely new (and were never designated "CDR" in the past), others are novel. This means that present day discussions will, in very material ways, shape their journey from research through development and demonstration to deployment in specific situations. In short, the discourse of CDR is poised to shape the practice of CDR, whereas only in future will the discourse-practice relationship be much more symmetrical. One very recent example of this is a study of public perceptions of CDR (Cox et al., 2020). Since the perceptions do not wholly precede the process of studying them, the terms and phrases deployed by the researchers to elicit perceptions have a performative quality. In turn, expressed perceptions will inform CDR research and policy "downstream." So it is that "saying" structures the field of "acting" in a somewhat one-sided process of co-production that may, but only later on, become more balanced and bi-directional (cf. Jasanoff, 2006).

Close and critical scrutiny of the language used to depict environmental phenomena and issues is hardly a new thing (e.g.,

\footnotetext{
${ }^{2}$ Anticipatory semantics are important within systematic and formalized processes of "anticipatory governance," where institutions are consciously adapted or designed to prevent or realize a future state of affairs seen as likely or un/desirable.
}

see Dryzek, 1997). ${ }^{3}$ But it remains relevant and hugely important, especially during "discursive windows." These are periods when the descriptive, explanatory, and evaluative terms that will define an emerging issue-field get established. Windows is a fairly apt metaphor here: the issues end-up being seen through a frame of a certain size and shape, whose glass is variously tinted, clear, or opaque to viewers depending on their angle of vision. The window is constructed by dominant actors or many actors of roughly equal influence, again depending on the context. ${ }^{4}$ For instance, in the lead up the UK Brexit referendum, the window was sufficiently large that Leavers and Remainers could be seen and heard by millions of people (see Charteris-Brown, 2019). Windows can be altered in time, but typically get fashioned in the first few years of a problem or issue coming to light [for instance, see Brown's 2016 analysis of how "sustainable development" has been progressively depoliticized since the mid-1980s in an attempt by some to "fix" its public meaning consistent with ongoing consumerism]. In the present case, CDR is the "issue," seen in relation to an array of other issues, like decarbonizing energy supply and reducing atmospheric temperature rises. Coexisting and overlapping discursive windows will likely emerge globally and in country-specific contexts. Discursive windows are usually established before what are called "policy windows" get opened: these are periods when sets of actions about new or existing issues or phenomena are instituted (see Rose et al., 2020). Windows can be re-opened and even demolished. This fact is well-illustrated by the vicissitudes of nuclear power in many countries, variously seen as an un/acceptable means of addressing the triple challenge of energy security, energy affordability, and climate change.

That I have referred to the language of CDR in metaphorical terms is very fitting because I want to focus on metaphor in the rest of this article. Metaphor, I contend, can be especially central to anticipatory semantics as discursive windows take shape. There are two obvious reasons why. First, all language is extensively metaphorical: metaphors are not, despite what some people may think, merely linguistic "devices" employed now and then for effect. They are part of the fabric of language, evenaccording to Lakoff and Johnson's (2003) classic study-the fabric of thought. Second, when confronted with new issues, situations or phenomena people are inevitably tempted to draw direct comparison between the familiar and the novel. In the present case, the very terms CDR and NETs have a strongly metaphorical quality, as well signifying techniques which themselves invite metaphorical description. This has already been evident in

\footnotetext{
${ }^{3}$ In many social science and especially humanities disciplines, a major focus on language, imagery and representation occurred during the 1980s and 90s. This "cultural turn" was sometimes presented as "social constructionism," since when there has been a neo-realist and neo-material (re)turn in disciplines like my own, human geography. Regardless of the vagaries of academic fashion, the close scrutiny of language to render the world meaningful and to shape action has never not mattered. A recent example of the value of discursive analysis, again in my own discipline, is provided by Adams (2020). He looks at water and its management as a partial product of its linguistic framing rather than the framing "reflecting" pre-existing meanings awaiting discovery and accurate representation.

${ }^{4}$ I adapt the notion of "discursive window" from the notion of a "policy window," first deployed by political scientists studying how policy agendas get built and instituted by competing political actors over time (e.g., see Kingdon, 1984).
} 
commentary within the expert community before and after the signing of the 2015 Paris Agreement (see Haikola et al., 2019). I now explore metaphor and CDR/NETs under four headings ("The nature and use of metaphor;" "The language of inclusivity and power;" "The dangers of metaphor;" and "Toward post-normal metaphor use"). While experts in the analysis of metaphor will find my observations fairly basic, this Perspective is addressed to those whose expertise is directly related to CDR/NETs. Keener awareness of language use among the latterin peer review journals, in discussions with environmental journalists, in citizen juries and in community planning fora, for instance-might help improve wider discussions of CDR techniques as their discursive window gets fashioned by many actors. We cannot afford to be casual or hasty in our use of metaphor when the stakes are so very high. So far, expert discussion has fallen prey to rather polarizing metaphors (see Haikola et al., 2019).

\section{THE NATURE AND USE OF METAPHOR}

Metaphor involves depicting one thing in terms of another. It's a linguistic convention designed to convey meaning, just as analogy, simile, hyperbole, alliteration, and metonymy are linguistic devices. Metaphor can be used rhetorically, that is to make a point or argument through exaggeration or special emphasis. But metaphor need not be used rhetorically, andas a linguistic device-it is also not, as noted, only utilized now and then. "The frequency of metaphors," notes Larson (2011: 4), "should not be surprising." Yet metaphors are not all of a piece. For instance, Newmark (1980), in his study of translation between languages, long ago identified several kinds of metaphor: namely, dead, stock, clichéd, and original metaphors. In the pragmatics of communication, the role of these metaphors is variable and contingent. For our purposes, the broad distinction between established and novel metaphors is less important than their prominence in specific situations In English, roughly one in every fifteen words is metaphorical. In that sense, metaphors are thoroughly ordinary. However, in some situations, certain metaphors loom large and clamor for attention. In the present context, we might say that as discursive windows take shape some metaphors can be especially potent in framing objects and issues. For those promoting them, these metaphors have the virtue of being memorable (sometimes strikingly so) and convenient.

Take SRM. In their paper, "Metaphors we die by?", Nerlich and Jaspal (2012) examined early newspaper reporting of "geoengineering" (between 1988 and 2010). They revealed the prominence of metaphor in handling the novelty and controversial character of SRM. For instance, a frequent and arresting metaphor was SRM as a "sunscreen," another was SRM as "medicine" administered to a sick "patient" (the Earth). Both metaphors were linked to the notion of a "climate catastrophe." This link, Nerlich and Jaspal suggested, was unlikely to permit widespread support among publics worldwide, and would put many risk-averse politicians off too (even as it drew attention to the need for drastic climate action). This is because they implied it might be "too late" to do other things to address climate change, creating feelings of defeat and fatalism and/or a reluctant reliance on technocrats armed with "last ditch" solutions. That is, however apt the metaphors were seen to be among geoengineering proponents, they were more likely than not to be unpersuasive and risked crowding out other ways of framing SRM.

As the SRM example shows, metaphors involve abstraction. They often "thingify" phenomena or issues by depicting them in terms of a known and well-defined object. This means metaphors are often poor at attending to relationships and entanglements among issues, problems or entities. Metaphors are also both cognitive and normative-cum-affective. They have a descriptive quality, linking "source" and "target" domains of reference through literal denotation. Indeed, a claim to some sort of descriptive accuracy or rough adequacy is implicit in virtually all metaphors. But they are also evaluative, often generating a positive or negative emotional reaction among their intended audiences. For instance, "sunscreen" is normally seen as good because it's intended to avoid the "bad" of skin cancer, making it (implicitly) "rational" to apply it. Meanwhile, in the field of conservation biology, the notion of "invasive species" is deeply loaded (see Larson, 2005, among others), having friend-enemy associations that are not necessarily apt when dealing with ecological entanglements. The socially accepted normative status of the source domain is thus used to shape normative intentions toward the emerging target domain.

The examples of sunscreen and invasive species remind us that prominent metaphors often work through chains of implicit semantic association and connotation. While ostensibly associating one thing or issue to another thing or issue, in reality metaphors often conjure-up a whole set of unspoken cognitive, normative, and affective references sedimented in our language. These references become quite important when key metaphors are employed repeatedly and rhetorically to define a new issue or object. Key metaphors tend to dominate the discursive spacefor instance, the more we use the language of NETs to think about climate change mitigation, the more we are invited to think of a global numbers game where we need to get below a baseline GHG concentration figure by "sucking" gases out of the atmosphere. This is consistent with long-standing discourse about a single envelope of intermixed GHGs (denominated in PPM) in need of global management. Meanwhile, other metaphors operate in less overt ways by virtue of the more "neutral" comparison between the source and target domains. For instance, climate researchers have quite successfully introduced the notion of a "carbon budget" into global discussions about climate policy since around 2005 (see Lahn, 2020). In Anglophone popular culture, the word "budget" is less loaded than the word "negative." Yet at some level it is still normative-affective, conjuring a complex set of economic associations and connotations about responsibility, taking, borrowing, and debt. Its semantic work is real but fairly quiet or surreptitious. Together, the notions of "negative" and "budget"- both signifying numerical targets and amountsremind us about another key element of prominent metaphors: namely, they tend to work in clusters. That does not mean each metaphor is wholly consistent with the others being used. But a corollary of the above mentioned pervasiveness of metaphor in 
social discourse is that metaphors come in groups by the time a discursive window is fashioned. The smaller the groups, the more constrained the hermeneutics of the issue in question are likely to be in the public domain. The more contested the issue, the more likely the principal metaphors are to polarize perspectives on it.

In sum, metaphors are pervasive in discourse but for many issues a selection of metaphors become prominent. They involve abstraction, are both cognitive and normative-affective, implicitly signify wider chains of meaning, and work in duos, trios, and clusters-though with some metaphors ultimately more influential than others as discursive windows get opened and gradually constructed.

\section{CDR, NETS AND THE LANGUAGE OF INCLUSIVITY AND POWER}

In the twenty-first century, there's a tendency for advanced science and technology to create new processes and objects which society is subsequently tasked with governing (ethically, legally, and practically). The leap-frogging developments in the world of academic and commercial genetics are a case in point. "Responsible research and innovation" (RRI) is now the mantra among many governments and scientists in order to avoid technology losing its societal moorings (e.g., it was a major focus of the EU Horizon 2020 funding programme from 2014). While some CDR/NETs techniques appear to be familiar and are framed as "natural," others are new and, given the ambitious 2015 Paris goals, are being discussed before their development and possible roll-out on a large scale. This is why the language used in discussion will matter so much. Even if some of the techniques are not "hi-tech" compared to say, driverless vehicles, CDR/NETs are being advanced by various scientists in the name of a scientifically defined "climate problem" (or crisis) and the related problem of national energy supply and security (since "decarbonization" is now an imperative). This not only gives "experts" a prominent role in framing CDR/NETs; it also lends legitimacy to the idea that CDR/NETs should be considered seriously in the political, commercial, and civic domains. The experts stand to be first-movers, setting the terms for broader discussion, even if-in the end-many others in the civic, commercial, and governmental domains will shape the discursive and policy windows. While there has yet to be a truly public debate about CDR/NETs, we have already seen that a few trained specialists have the key voices so far (e.g., Kevin Anderson, Glen Peters, and Klaus Lacker). Metaphor has been integral to their messages (e.g., see Anderson and Peters, 2016; Lackner et al., 2016).

If certain metaphors will probably loom large in the debates to come, we might ask: what are some of the dangers attending to their use? To answer this question we need to anticipate the likely contexts of future discussion. The terms CDR and NETs encompass disparate measures, so much so that some have asked whether it's at all sensible to consider them togethernotwithstanding their common aim to reduce GHG emissions in light of the Paris Agreement targets (Bellamy and Geden, 2019). Even so, it's likely that several measures will be aggregated in global debates (especially in the United Nations) and that national level discussions will also ensue (for instance, recall that the mid-1990s controversy over field testing genetically modified crops caused the British New Labor government to instigate a consultation across England, Northern Ireland, Scotland, and Wales). More locally, just as fracking has sparked community opposition in the UK, USA and elsewhere, so certain proposals to test specific CDR/NETs are likely to spark strong local interest in rural and peri-urban areas, or in coastal areas adjacent to proposed experiments in marine geoengineering. The local debates are much more likely to attend to the specific details of certain CDR/NETs techniques than are national and global debates (which will tend to focus on general questions of principle, size and scope, referenced to strategic climate, and energy goals). But the local debates are also likely to be discursively framed by these prior global and national discussions, often coming later in the "window making" process. Throughout, a common denominator is that discussions of most (if not necessarily all) CDR/NETs in many (if not all) venues will have a deliberative character. In other cases, conflict will arise or people will be silenced, rendered passive or ignored in various ways. By and large, the latter cases will arise more often in countries with weak or non-existent histories of democratic rule. Yet in erstwhile democracies, social media, the decline of deference to certified experts and other forces are often conspiring to render deliberation a process of heat without much light among interlocutors.

The reasons why CDR/NETs are likely to spark societal debate are not difficult to fathom. First, the combined scale of CDR/NETs needed to meet the Paris goals is such that countries will need to consider each other's rights and responsibilities in the process. Second, the speed at which GHG removal techniques will need to be deployed means wide consultation will again be necessary across the globe. Avoidance of such consultation may be a sign of power and special interests in play, perhaps through labeling some CDR/NETs techniques in ways that conceal their significance for ecology and people. Third, within specific countries the immediate knock-on effects of large-scale deployment (e.g., of biomass with carbon capture and storage on agricultural land for food) will likely oblige governments to consult citizens in many cases. In several situations, the effects might be perceived as worse than the impacts of unabated climate change. In other cases, government or commercial actors may want to downplay the effects in order to get $\mathrm{CDR} / \mathrm{NET}$ projects actioned. Fourth, we live in an age of protest where, in democracies as well as more autocratic states, people routinely express their right to be considered and heard. Witness Extinction Rebellion, among many others. When CDR/NETs deployment significantly impacts peoples' local environment-be the people wealthy second-homers in rural Germany, campesinos in Mexico or aboriginal Australians-then we might expect some sort of debate to ensue between stakeholders (be it by design or through oppositional action).

In this context, metaphor can serve the process of deliberation more or less well. Deliberation can be judged according to its quality and range. Quality is a question of how sophisticated debate is and whether interlocutors are truly listening to each 
other. One of the paradoxes of the present is that we live in "an information age" inhabited by more university graduates than ever before, yet where the quality of public debate about important issues is typically low. The Brexit issue in the UK demonstrated this graphically: an exceedingly complex, highstakes question ("stay or leave?") was answered using sound bites and simplistic slogans by antagonists between 2016 and 2019. The misuse of social media, strong bias in some news reporting organizations (notably Fox News) and the rise of some populist politicians (notably, Donald Trump, Jair Bolsinaro, Boris Johnson, and Vladimir Putin) have also created a "post truth" environment where mutual trust and common ground seem in short supply as misinformation proliferates. Many political theorists advocate for special deliberative measures (e.g., citizen juries, public consultations, consensus conferences) in order to improve shared understanding, to build trust, to clarify reasoning, to facilitate subsequent decision making and to legitimize action. Such measures can address the need to be inclusive of perspectives, that is to build a sufficient range of values and arguments into debate so that mainstream or elite perspectives are not assumed to be the best or only starting point. Yet many critics in social science (e.g., Wilson and Swyngedouw, 2014) believe we now live in a "post-political" age where debate is stymied or stage-managed such that "radical" or "alternative" political axioms and goals are not given a proper hearing and remain on the social margins.

Clearly, what counts as a "properly political" debate it itself a political question, the answer to which will be inflected by existing social power relationships. Relatedly, there is no "model" of "good deliberation" that can rise above all contexts as a standard-setter. ${ }^{5}$ Even if there was, profound questions arise about how far good deliberation can be instituted in our deeply imperfect world. Even so, we can identify some broad threats that unthinking, special-interest driven, rhetorical, or very strategic metaphor use can pose to rich and inclusive dialogue about CDR/NETs. When realized, the threats might limit understanding, obscure complexity, marginalize some voices and precipitate weakly justified actions that lack legitimacy among those they affect.

\section{THE DANGERS OF CONVENTIONAL METAPHOR USE}

The quality of global, national, and local-scale discussion of CDR/NETs techniques - from the research and development phase through to long-term, large-scale deployment-will be strongly conditioned by the principal metaphors employed to characterize them in the next few years (unless we were to somehow forgo use of prime metaphors, something I will consider briefly near the end of this article). This much is obvious when we reflect back on AIDS-the so-called "gay disease"as it became a matter of medical, governmental, and public concern during the 1980s. In her influential book on AIDs

\footnotetext{
${ }^{5}$ Chilvers and Kearns (2020) outline the cutting-edge of approaches to reflexive, democratic public consideration of science and technology, but the reality is their "gold standard" will simply be infeasible in many parts of the world.
}

and metaphor, Sontag (1989) showed how the notions of a "plague," a "cancer," and "polluted" bodies served to stigmatize gay people in the USA and beyond. The discursive window, she demonstrated, became quite hard to reopen and reframe thereafter. Analogously, the risk is that poor metaphor use-we might even say the employment of major metaphors, period - will crowd-out richer ways of discussing the nature and implications of CDR/NETs. As we will see in the next section, by "richer" I do not simply mean "empirically accurate" to the techniques in question, but also inclusive of value-based, socially contingent, situated appraisals of these techniques relative to climate change and related challenges.

Given the context in which the CDR/NETs issue has risen to prominence, the risks are clear enough and all involve undue simplification of cognitive, normative, and affective complexity and diversity:

\section{Risk 1: Narrow Abstraction and Fetishization Through Conventional Metaphors}

Already, it's evident that CDR/NETs risk being narrowly framed in terms of material-physical phenomena (e.g., altering the alkinity of ocean water) and their contribution to an overarching goal of reducing GHG concentrations. Metaphors such as "sinks" and "capture" provide noun or verb-based references to source domains that conjure-up well defined images of removal and containment. Greenhouse gases, and the global atmosphere more broadly, risk being objectified as discrete entities that CDR/NETs can materially manage. While this circumscription may seem factually appropriate - after all, anthropogenic climate change is occurring and GHG concentrations are rising-it screens-out a whole set of ontological, causal and normative connections between the "problem" at hand and CDR/NETs as putative "solution." A recent paper about SRM and new agricultural biotechnology highlights the problem of narrow abstraction and the fetishization of phenomena. Inspired by the analytical tradition of Frankfurt School critical theory, Gunderson et al. (2020) focus on the language of technology assessment. They identify four potential problems, namely that (i) the political economic determinants of a given technology are hidden; (ii) the technology may conceal chronic socialecological contradictions; (iii) the technology may reproduce existing, unjust social conditions; and (iv) the technology may be used for more rational or emancipatory ends in different social conditions but these possibilities are occluded. While metaphor is not the focus on their paper, prime metaphors can underpin all four problems of invisibilization.

\section{Risk 2: Urgency and Global Risk Trump Other Concerns Through Evocative Metaphor}

As Nerlich and Raspal's study of SRM discourse showed, the connection of simple metaphors about CDR/SRM to other metaphors that evoke crisis, emergency, and calamity is very possible in the immediate future. One of these other metaphors is the "ticking clock," another is "climate debt" and still another 
is "climate overshoot." These metaphors are very good indeed at triggering an emotional response. But often, as noted above, it's a negative and de-motivating one (fear and anxiety are as likely to eventuate as a radical, proactive mentality). The metaphors have frequently been employed by geoscientists who are alarmed at chronic foot-dragging among the world's governments. They are also routinely used by environmental NGOs like Greenpeace and by public figures such as David Attenborough, Naomi Klein, Bill McKibben, and George Monbiot. While it may seem as if these metaphors are scientifically validated (i.e., evidentially determined), there is in fact a "gap" between "is" and "ought" that can only be bridged by contestable and revisable judgements about whether, how widespread and how urgent a global "emergency" actually is (Hulme et al., 2020). Anxiety over how to somehow close the gap has been evident in conservation biology for years regarding the global loss of biodiversity (Robbins and Moore, 2013). Without in any way wanting to undermine the serious implications of climate research, it's possible to imagine using less dramatic, less globally-referenced, and less climate-centric metaphors to represent the de/merits of various $\mathrm{CDR} / \mathrm{NET}$ s projects at different spatial scales. One obvious point to make here is that not every project will, in reality, be equally "necessary" in order to tackle to "climate crisis," regardless of what some proponents may say. Another is that some projects could legitimately be metaphorized with reference to primarily local concerns rather than generalized global risks. At this scale, the metaphors might more helpfully refer to livelihoods, rights, cultural traditions, and environmental quality issues. Community protests against fracking projects in the UK and beyond have already demonstrated this: the protestors reframed fracking so that it was no longer represented (narrowly) in terms of risk (posed to the environment) and energy security at the national scale.

\section{Risk 3: CDR/NETs Metaphorized as "Environmental" Interventions That Are Required of "Society"}

Directly linked to the previous two risks is a third one: that metaphors be hitched to the society-nature dualism in ways that make CDR/NETs appear as an environmental requirement of certain societies. This is not to say that, as whole, the GHG removal techniques are not urgently needed. But metaphors about CDR/NETs such as their capacity to "restore balance," "cool the planet," or "take the foot off the accelerator" can serve to distract attention from the equally important need for conventional mitigation measures, for far-reaching adaptation measures and, more broadly for structural changes to fossilfueled, capitalist economies worldwide. In other words, the field of societal "requirements" is potentially wide-open, with some countries and social strata needing to make bigger contributions than others. So-called "environmental imperatives" involve contestable social appraisals of the nature, level, and distribution of risk and do not reside "objectively" in changing natural systems where the precautionary principle is required to be observed. For instance, in some quarters "dead-lineism" is currently hypostatizing these appraisals as if mandated by the “environmental crisis" (see Asayama et al., 2019). In reality, these appraisals can be realized through a range of possible actions that can be metaphorized every bit as much as CDR/NETs can be.

\section{Risk 4: Natural CDR/NETs Delegitimize Some "Artificial" Ones Through Binary Metaphorizing}

As Bellamy and Osaka (2020) have recently pointed out, a heuristic distinction between natural and artificial CDR/NETs is taking hold. Broadly, it corresponds to low-tech and hightech interventions, with few of the latter yet fully developed. As the case of afforestation indicates, "natural" interventions can broadly do what the living world might do if left to its own devices, whereas artificial ones are more-or-less "unnatural." In turn, the distinction invites certain metaphors to be attached to these broad groupings of techniques or to specific techniques within them. For instance, natural CDR/NETs can be framed as "rebalancing" a world knocked off-track through reckless human behavior. Meanwhile, some artificial approaches can be framed as "playing God" through uncontrolled experiments in Earth System management. Yet, as Bellamy and Osaka note, where to place the natural-artificial boundary is not that obvious. Meanwhile, many ostensibly "natural" techniques could, on closer inspection, involve highly artificial components (such as planting non-native trees en masse in anticipation of moving ecological belts on a warming planet). Metaphor can too easily be used to "fix" the meanings of certain CDR/NETs across the natural-artificial divide, in the process simplifying matters unduly.

\section{TOWARD POST-NORMAL METAPHOR USE}

We live in post-normal times, which-riffing on the notion of "post-normal science" (Funtowicz and Ravetz, 1993) - is to say that our's is an era where high-stakes decisions must be taken urgently but where (i) uncertainty about possibly profound outcomes is large so that (ii) decisions must be based as much on value commitments as on robust knowledge. Acting now in anticipation of a hard-to-understand but potentially very threatening future is becoming normalized-even if it's our great grand-children who might suffer the largest burdens or reap the rewards of our hopefully timely, considered actions. We need anticipatory discourse adequate to this challenge. The four risks identified above would, should they be realized, be reflective of a "normal" use of metaphor. That is, prime metaphors here help interlocutors to make points, or assert claims, by simplifying complexity in ways that seem intuitive and persuasive because referenced to familiar objects and acts. But in our postnormal times, we need language that is more adept at handling the material and semiotic knottiness of the issues, covering both cognitive and normative issues with sophistication. To complicate the complexity, CDR/NETs interventions will need to be understood in their specific local and national context but also discussed more abstractly in wider considerations of intergovernmental action to tackle climate change. In each case, metaphor will have an important role to play-just as it will in any major proposal for new infrastructure or for systemic changes to a society referenced to mitigation and adaptation imperatives. 
In post-normal discourse about CDR/NETs, metaphors would be employed in the service of rounded analyses of the issues, perhaps in the form of extended and even competing narratives. The traditional language of science and technology can only be one part of such analyses, not the main part. In rich narratives, metaphors do not short-circuit complexity but help, rather, to reveal it. It may seem to trivialize the issues by emphasizing "story-telling." But textured narratives about CDR/NETs in the near and longer-term future will help to capture the tangle of pros and cons, and the wider implications of the various "natural" and "artificial" techniques should we choose to forgo or employ them. ${ }^{6}$ As we saw earlier, metaphors are never only about the things or issues they seemingly make literal reference to. They implicate things beyond the ostensible semantic targets (Seligman and Weller, 2019). Post-normal metaphor use in a narrative context would help to open-up consideration of how CDR/NETs involve questions of, to give a few examples, energy supply, rights to land and water, cultural histories of resource use, food supply, the rights of future generations, group identities, and more besides. It would make a virtue of chains of hermeneutic association and connotation. It would be "knowing" in its employment of metaphor and dominant metaphors would be looked upon with suspicion because of their potential for reductionism. For example, metaphors that highlight the environmental merits of CDR/NETs would be complemented by others that point to its possible negative knock-on effects or uncertain outcomes. In each case, the major epistemic uncertainties prevailing mean that the metaphors would need to be explicit about the relative value judgements written into them.

To talk metaphorically about metaphor, in post-normal discourse great efforts would be made to attend to the dynamic (often frayed) "tapestry" of life not merely the separate "threads." "Metaphor scenarios" would be the norm (Musolff, 2016) and rarely would a CDR/NETs project, or groups of them, be treated in abstraction from a plethora of entanglements. This form of discourse is demanding because, as with any advanced form of analysis, it requires people to hold in their heads many arguments (based on contestable values) and evidential claims. Post-normal discourse is designed to enable rich "communicative reason," albeit in a world chock-full of inequality that (i) denies interlocutors a level communicative platform and (ii) fosters nefarious, self-interested communicative acts insensitive to the common good. It is geared toward inclusive, well-justified decision making about practical action. The expert community can play its part here by using metaphor sensitively and by being explicit about the value judgements animating them.

The way I have depicted things so far, we need skillful use of metaphor to allow more holistic and integrative forms of understanding that might highlight tensions and contradictions. But, useful as that is, it's not, in fact, sufficient. It implies that using more metaphors, connecting to more elements of reality, is

\footnotetext{
${ }^{6}$ There is a growing interest in narrative as a communicative device in various areas of practice-relevant environmental research. See, for instance, Moezzi et al. (2017). However, in the basic sense of "story telling" narratives can be one sided, partial and simplistic. In the present context, for example, Asayama and Ishii (2017) highlight one sidedly optimistic CDR narratives in several Japanese newspapers between 2006 and 2013 .
}

the next discursive step as we anticipate a world with CDR/NETs in it. But the challenge is to grapple with alternate realities, both present and future. A "one world" ontology commits us to using metaphor to point to a myriad of issues and phenomena so as to foster some sort of consensus about reality both present and future. Yet humans' capacity for interpretive difference, and alternative ways of living practically, makes "deep pluralism" something to be reckoned with locally, nationally, and globally. Post-normal metaphor use could and should be used to foster dissonance about the ontological, affective and value-dimensions of CDR/NETs (see Veland et al., 2018). This would push against the claimed "post-political" tendencies of our time. Different metaphor scenarios will say as much about the people presenting them as about the material realities being referred to in discourse.

This is acutely obvious in ostensibly post-colonial settings in the Anglophone world. For instance, consider a recent study of proposed dam and lock removals along the Upper Mississippi River Gorge in Minnesota (Koban, 2020). Like any local CDR/NETs proposal of reasonable scale, the removals will make a real difference to both people and environment in the region. Koban shows that there are not, in far, shared metaphors or "best metaphors" that can unite disputants over the river restoration plan and the subsequent management of a more "natural Mississippi" (likewise, see Morehouse and Cigliano, 2020 on ice retreat in northern Canada and beyond). In fact, in indigenous cultures "things" are usually not compared to other things but, instead, regarded as substantively connected (for an example of such constitutive relationality, see Stewart-Harawira, 2020). Here metaphor in the Anglophone sense reaches its limits, even when used sensitively. This said, the notion of a kaleidoscope of perspectives on ostensibly the same river does, perhaps, help us to see the bridging potential of metaphor to acknowledge cognitive and normative incommensurability en route to some of sort of accommodation that permits action on the ground.

This mention of limits takes me to the logical conclusion of the analysis. While, according to Lakoff and Johnson (2003), metaphor is unavoidable, for CDR we should perhaps press for the avoidance of prime metaphors of any kind. However, adeptly handled by some, they risk debasement by others and will doubtless serve to simplify complicated issues even if several are in play. One can speculate as to why. Whether one takes a sociohistorical or evolutionary approach to language, it is plausible to suggest that humans now operate beyond the physical range to which our inherited vocabularies were adapted. Our metaphors, at least in the West, seem to reflect a disappearing world where relevant objects and activities were close by and broadly manageable in practice. We need to frame CDR in the richest and widest possible ways (economic, moral, aesthetic, and beyond), even when the technical efficacy of one or other technique is the most pressing matter at hand.

\section{CONCLUSION}

In his classic essay "Politics and the English language," Orwell (1946) reminded his readers that language is far too important in its effects to be used carelessly or unthinkingly. He strongly disputed "the half-conscious belief that language is a natural growth and not an instrument which we shape for our 
own purposes." Likewise, I've argued here that close, critical attention to metaphor could trigger rich debates about key issues relating to CDR/NETs. Equally, it can be used to facilitate more shallow discussions. But who, in the end, will shape metaphor for the purposes of the many not the few? Clearly, in the discursive life of CDR/NETs, people in the expert community-scientists, technicians, consultants, marine and landscape planning academics, and so on-will have a key role to play. This is because they enter the story early on, as evidenced in recent years by the inclusion of CDR/NETs in the IPCC's future climate scenarios (see Beck and Mahony, 2018). They thereby possess quite a lot of discursive power, providing words, images, and storylines that will shape subsequent understandings of the realities of projects to lock-up GHGs in long-term storage. If metaphors can serve to govern our thoughts and actions then we must work hard to govern our use of metaphor. Science and technology, be it "green" or more hi-tech, is profoundly reliant on metaphor in many acts of communication. The best venues to test and challenge these metaphors are deliberative ones where mini-publics, working with thoughtful people in planning, policy studies, and Science \& Technology Studies, can have their own say in light of local and national concerns. ${ }^{7}$

As RRI rises up the agenda in many parts of the world (see Low and Buck, 2019; and the special issue of Science, Technology \& Society 25, 2), we might reflect on the fact that

\footnotetext{
${ }^{7}$ Haikola et al. (2019) study news media and science media reporting of BECCS, especially from 2013 to 2018 . They show how a very few interlocutors in the world of science, by and large, dominated the fairly small amount of discussion about BECCS. The discussion, at that early stage, was generally about the ill/logic for turning to BECCS on a large scale in the future. Haikola et al. conclude that the discursive window has evolved toward a sullen acceptance that BECCS are "risky but necessary." They also conclude that post-normal discourse tends to be temporary, linking it to the pressures to debate BECCS exerted by the Paris meeting of the parties to the UNFCCC in 2015. I am not so sure. Since BECCS have not yet enjoyed widespread and truly public discussion, it is possible that the window will be shaped many times again in different countries. The potential for "normal" discourse about the post normal question of CDR/NETS is high and to be avoided.
}

\section{REFERENCES}

Adams, P. C. (2020). Language and groundwater: symbolic gradients of the Anthropocene, Ann. Am. Assoc. Geogr. doi: 10.1080/24694452.2020.1782724

Anderson, K., and Peters, G. (2016). The promise of negative emissions-response. Science 354, 714-715. doi: 10.1126/science.aal2610

Asayama, S., Bellamy, R., Geden, O., Pearce, W., and Hulme, M. (2019). Why setting a climate deadline is dangerous. Nat. Clim. Change 9, 570-572. doi: 10.1038/s41558-019-0543-4

Asayama, S., and Ishii, A. (2017). Selling stories of techno-optimism? The role of narratives on discursive construction of carbon capture and storage in the Japanese media. Energy Res. Soc. Sci. 31, 50-59. doi: 10.1016/j.erss.2017.06.010

Beck, S., and Mahony, M. (2018). The politics of anticipation: the IPCC and the negative emissions technologies experience. Glob. Sustain. 1, 1-8. doi: $10.1017 /$ sus.2018.7

Bellamy, R., and Geden, O. (2019). Govern $\mathrm{CO}_{2}$ removal from the ground up. Nat. Geosci. 12, 874-879. doi: 10.1038/s41561-019-0475-7

Bellamy, R., and Osaka, S. (2020). Unnatural climate solutions?. Nat. Clim. Change 10, 98-99. doi: 10.1038/s41558-019-0661-z

Brown, T. (2016). Sustainability as empty signifier. Antipode 48, 115-133. doi: $10.1111 /$ anti.12164 our responsibilities to people reside, in large part, in language first of all. This is why social scientists and humanists, along with technical experts at the CDR/NETs coal-face, must become deeply aware of the politics and potency of their words in our post-normal times. The words, rightly, will signify things that go beyond science and technology strictly speaking. A balance between clarity and sophistication will be needed. The forces of populism, misinformation, fake news, propaganda, and Manichean thinking may otherwise threaten the quality of discourse about major infrastructural decisions relating to people and planet. The problem is that is certain key communicative domains, such as tabloid journalism, social media platforms and even parliaments, mature communication is not welcome and "normal" discourse is ill-suited to advance human interests.

\section{DATA AVAILABILITY STATEMENT}

The original contributions presented in the study are included in the article/supplementary material, further inquiries can be directed to the corresponding author.

\section{AUTHOR CONTRIBUTIONS}

The author confirms being the sole contributor of this work and has approved it for publication.

\section{FUNDING}

Funding for open access publishing was generously provided by the University of Manchester.

\section{ACKNOWLEDGMENTS}

Oliver Geden provided very formative editorial guidance and two reviewers offered rich and insightful commentary on the initial version of this article. I'm very grateful to all three for helping improve it.

Charteris-Brown, J. (2019). Metaphors of Brexit. London: Palgrave.

Chilvers, J., and Kearns, M. (2020). Remaking participation in science and democracy. Sci. Technol. Hum. Values 45, 347-380. doi: $10.1177 / 0162243919850885$

Cox, E., Spence, E., and Pidgeon, N. (2020). Public perceptions of carbon dioxide removal in the United States and the United Kingdom. Nat. Clim. Change 10, 744-749. doi: 10.1038/s41558-020-0823-z

Dryzek, J. (1997). The Politics of the Earth. Oxford: Oxford University Press

Epstein, C. (2008). The Power of Words in International Relations. Cambridge, MA: MIT Press.

Fajardy, M., Patrizio, P., Daggash, H. A., and Mac Dowell, N. (2019). Negative emissions: priorities for research and policy design. Front. Clim. 1:6. doi: 10.3389/fclim.2019.00006

Funtowicz, S., and Ravetz, J. (1993). Science for the post-normal age. Futures 31, 735-755. doi: 10.1016/0016-3287(93)90022-L

Gunderson, R., Stuart, D., and Petersen, B. (2020). Materialized ideology and environmental problems. Eur. J. Soc. Theory 23, 389-410. doi: $10.1177 / 1368431019839252$

Haikola, S., Hansson, A., and Anshelm, J. (2019). From polarization to reluctant acceptance: BECCS and the post-normalization of the climate debate. J. Integr. Environ. Sci. 16, 45-69. doi: 10.1080/1943815X.2019.1579740 
Hulme, M., Lidskog, R., White, J. M., and Standring, A. (2020). Social scientific knowledge in times of crisis. WIRES Clim. Change 11:e656. doi: $10.1002 /$ wcc. 656

Jasanoff, S. (2006). States of Knowledge. New York, NY: Routledge.

Kingdon, J. (1984). Agendas, Alternatives and Public Policies. Boston, MA: Little Brown.

Koban, J. (2020). Ecological restoration or healing?: conflicting ontologies and missed opportunities in public debates surrounding Mississippi River Gorge restoration. Environ. Commun. 14, 582-559. doi: 10.1080/17524032.2019.1696854

Lackner, K., Aines, R., Atkins, S., Atkisson, A., Barrett, S., Barteua, M., et al. (2016). The promise of negative emissions. Science 354:714. doi: $10.1126 /$ science.aal 2432

Lahn, B. (2020). Changing climate change: the climate budget and the modifying work of the IPCC. Soc. Stud. Sci. doi: 10.1177/0306312720941933

Lakoff, G., and Johnson, M. (2003). Metaphors We Live By. Chicago: Chicago University Press.

Larson, B. (2005). The war of the roses. Front. Ecol. Environ. 3, 495-500. doi: 10.1890/1540-9295(2005)003[0495:TWOTRD]2.0.CO;2

Larson, B. (2011). Metaphors for Environmental Sustainability. New Haven, CT: Yale University Press.

Low, S., and Buck, H. J. (2019). The practice of responsible research and innovation in 'climate engineering.' WIRES Clim. Change 11:e644. doi: 10.1002/wcc.644

Moezzi, M., Janda, K., and Rotmann, S. (2017). Using stories, narratives, and storytelling in energy and climate change research. Energy Res. Soc. Sci. 31, 1-10. doi: 10.1016/j.erss.2017.06.034

Morehouse, H., and Cigliano, M. (2020). Cultures and concepts of ice: listening for other narratives in the anthropocene. Ann. Am. Assoc. Geogr. doi: 10.1080/24694452.2020.1792266

Musolff, A. (2016). Political Metaphor Analysis: Discourse and Scenarios. London: Bloomsbury Academic.

Nerlich, B., and Jaspal, R. (2012). 'Metaphors we die by? Geoengineering, metaphors, and the argument from catastrophe. Metaphor Symbol 27, 131-147. doi: $10.1080 / 10926488.2012 .665795$
Newmark, P. (1980). The translation of metaphor. Babel 26, 93-100 doi: 10.1075/babel.26.2.05new

Orwell, G. (1946). Politics and the English language. Horizon 13, 252-265.

Robbins, P., and Moore, S. (2013). Ecological anxiety disorder, Cult. Geogr. 21, 3-19. doi: 10.1177/1474474012469887

Rose, D., Mukherjee, N., Simmons. B. I., Tew, E. R., Robertson, R. J., Vadrot, A. B. M., et al. (2020). Policy windows for the environment: tips for improving the uptake of scientific knowledge. Environ. Sci. Policy 113, 47-54. doi: 10.1016/j.envsci.2017.07.013

Seligman, A., and Weller, R. (2019). How Things Count As The Same. Oxford: Oxford University Press.

Sontag, S. (1989). Illness as Metaphor and AIDS and Its Metaphors. New York, NY: Doubleday.

Stewart-Harawira, M. W. (2020). Troubled waters: maori values and ethics for freshwater management and New Zealand's fresh water crisis. WIRES Water 7:e1464. doi: 10.1002/wat2.1464

Veland, S., Scoville-Simonds, M., Gram-Hanssen, I., Schorre, A. K., El-Khoury, A., Nordbø, M. J., et al. (2018). Narrative matters for sustainability the transformative role of storytelling in realizing $1.5^{\circ} \mathrm{C}$ futures. Curr. Opin. Environ. Sustain. 31, 41-47. doi: 10.1016/j.cosust.2017.12.005

Wilson, J., and Swyngedouw, E. (2014). "Seeds of dystopia: post-politics and the return of the political," in The Post-Political \& Its Discontents, eds E. Swyngedouw and J. Wilson (Edinburgh: Edinburgh University Press), 1-15.

Conflict of Interest: The author declares that the research was conducted in the absence of any commercial or financial relationships that could be construed as a potential conflict of interest.

Copyright (C) 2020 Castree. This is an open-access article distributed under the terms of the Creative Commons Attribution License (CC BY). The use, distribution or reproduction in other forums is permitted, provided the original author(s) and the copyright owner(s) are credited and that the original publication in this journal is cited, in accordance with accepted academic practice. No use, distribution or reproduction is permitted which does not comply with these terms. 